\title{
Factors affecting male partners' involvement in maternity waiting home utilization in North Achefer district, Northwest Ethiopia: a cross-sectional study
}

\section{Getachew Asmare}

USAID Caring for Vulnerable Children (CVC) project, Bahir Dar, Ethiopia

Dabere Nigatu ( $\square$ daberen@yahoo.com )

Bahir Dar University College of Medical and Health Sciences https://orcid.org/0000-0001-7303-6723

\section{Yamrot Debela}

Bahir Dar University College of Medical and Health Sciences

\section{Research article}

Keywords: Male involvement, male partners, maternity waiting home utilization, Ethiopia

Posted Date: January 16th, 2020

DOl: https://doi.org/10.21203/rs.2.21046/v1

License: (c) (i) This work is licensed under a Creative Commons Attribution 4.0 International License.

Read Full License 


\section{Abstract}

Background: Maternity waiting home is a direct strategy to improving newborn and maternal survival. The utilization of maternity waiting home, however, remains very low in Ethiopia. The involvement of men in maternal health programs is a key strategy to increase utilization of various maternal health services including maternity waiting home. Thus, this study is aimed to determine the proportion of and factors affecting male partners' involvement in maternity home utilization.

Methods: A community-based cross-sectional study was conducted from November 01 - December 30, 2018. A total of 403 male partners were involved in the study. Data were analyzed by statistical package for social science (SPSS) version 23. Independent predictors were identified by multivariable logistic regression model. Adjusted odds ratio (AOR) with 95\% confidence intervals (CI) was reported.

Results: The proportion of male partner's involvement in maternity waiting home utilization was $55.6 \%$ $(50.71,60.45)$. Age ( $\mathrm{AOR}=0.88,95 \% \mathrm{Cl}=0.82-0.94)$, knowledge ( $\mathrm{AOR}=4.75,95 \% \mathrm{Cl}=2.65-8.49)$, decision making power ( $A O R=4.00,95 \% \mathrm{Cl}=1.38-11.57)$, and male partners' who got counseling about maternity waiting home during spousal antenatal care visit (AOR=9.15, 95\% $\mathrm{Cl}=3.34-25.03)$ had statistically significant association with male partner's involvement in maternity waiting home utilization.

Conclusions: Nearly, a half of male partners were involved in maternity waiting home utilization. Men's age, knowledge, decision making power, and receiving counseling were factors for male partner involvement in maternity waiting home utilization. Targeted interventions on increasing men's knowledge about maternity waiting home and changing patriarchal thinking in the society can improve men's involvement in maternity waiting home utilization.

\section{Introduction}

Global experiences shows that more than $80 \%$ of maternal deaths could have been prevented by appropriate and timely interventions performed by skilled professionals in a conducive environment $[1,2]$. In 2016, only $26 \%$ of women in Ethiopia gave birth at health facility. This rate is among the lowest in the world. The reasons for non-use includes notions that facility delivery is not necessary or customary, as well as physical distance to the facility and lack of transportation[3]. Many years since maternity waiting home (MWH) is articulated as a direct strategy to increase health facility delivery, and improve maternal and newborn survival[ $[4,5]$. Maternity waiting home are residential facilities located near a hospital or a health center that allow pregnant women to wait for the onset of labor. Once labor starts, women would move to the health facility so that they can be assisted by a skilled birth attendant[6]. Pregnant women from remote areas, women with gestational age greater or equal to 38 weeks, women with previous pregnancy/delivery problems (previous preterm labor, previous still birth, previous cervical tear), or women with known risk declared by health professional are eligible for accommodation at $\mathrm{MWHs}[7,8]$. In 2016, a survey conducted in four regions of Ethiopia reported that $70 \%$ of health centers had maternity waiting homes[9]. 
Although MWH started in the late 1980s in Ethiopia[6], the service uptake remains low because of sociodemographic, economic, cultural, gender- and facility-related constraints[7, 9]. Moreover, in developing countries including Ethiopia most community give a low position to women which put them either under collective decision making with their partner or completely depend on the male partner's decision on issue that affects their health[10]. In order to overcome such problems, nearly two decades before to this days, the concept of male involvement in maternal health is being promoted as an essential element of World Health Organization initiative for making pregnancy and childbirth safer[11]. The rationales for seeking to involve men includes a view of men as gatekeepers and decision-makers for prompt access to health services; as responsible partners of women; as an important member of the community; and men's preference to be involved as fathers/partners[12]. For example, 55\% women in Ethiopia to $95 \%$ women in Kenya need their husband's permission to use $\mathrm{MWH}[13,14]$ while about one-third $(33 \%)$ of mothers in Ethiopia experienced refusal of admission by husbands[9]. We found that studying men's involvement in the maternity waiting home use has paramount importance for policy-makers, programmers and health care planners to design evidence-based interventions. Therefore, this study is aimed to determine the proportion of and identify the factors that affect male partners' involvement in maternity waiting home utilization in Northwest Ethiopia.

\section{Methods}

\section{Study design and settings}

A community-based cross-sectional study was conducted in North Achefer district from October $1^{\text {st }}, 2018$ to December $30^{\text {th }}, 2018$. The district is located in West Gojjam Zone, Amhara regional state, Ethiopia. It has a total of 27 kebeles ("kebele" is the lowest administrative unit in Ethiopia). Regarding health infrastructures, it has one primary hospital, seven health centers, five private clinics and twenty seven health posts. During the time of data collection, there were seven maternity waiting homes at each health center in the district, but only five of the health centers had functional maternity waiting homes [15].

\section{Sample size and sampling procedure}

Primarily, we proposed to include 442 male partners in the study while actually 403 male partners were involved in the study. The sample size was determined by using single population proportion formula. In North Achefer district, only five health centers had functional maternity waiting homes. First, the principal investigator identified 662 mothers who were used MWH in the last one year from maternity-waitinghome-users registration book. Then, residential profile (kebeles and gott's) of mothers were identified from maternity waiting home registration book. Finally, mothers were selected by table of random numbers. Maternity-home-user mothers from nearby districts and whom husband diseased or divorced were excluded. Males who were currently living with their spouse were considered in the study.

\section{Study variables and measurements}


Male partners were interviewed using structured Amharic version questionnaire. Trained data collectors and supervisors were involved in the data collection process. The interview was done in the respondents' residential house. In case selected respondent was not available at the time of first home visit, two times revisit was made.

The questionnaire comprised of socio demographic variables (age, educational status, wealth index, occupation and number of children); participant's spousal obstetric history (previous still-birth, previous health facility delivery, length of stay at MWH, ANC follow up, history of spousal obstetric complication); health facility related variables (presence of basic social services, presence of ambulance, and receiving daily follow up at MWHs); male partner's gender thinking (number of wives, decision making power); and male partner's knowledge and attitude towards MWH. Five knowledge items were used to assess male partner's knowledge about maternity waiting home. All correct responses on five items were added to produce composite index. We used eight items with five points Likert scale to assess male partner's attitude towards maternity waiting home. The sum score was generated by adding individual score on each item. Those men who score above median were considered as having positive attitude towards maternity waiting home utilization otherwise taken as having negative attitude.

The outcome variable for this study was male partners' involvement on maternity waiting home utilization. Six items were used to measure male partners' involvement on maternity waiting home utilization. The items used includes male partner participation in decision to rest their spouse to $\mathrm{MWH}$, accompanying spouse while she went to $\mathrm{MWH}$, provide financial support while spouses went to/at maternity waiting home, avail food while spouses were at MWH and looked after the home and/or the remaining children while the spouses were at MWHs. Each item had yes or no response options and coded 1 yes or 0 no. We added the score on each item to generate a composite index for male involvement in MWH utilization. Those male partners who score less than three were considered as poor male involvement while those who score greater than or equal to three were considered good male involvement.

\section{Data analysis}

Data were checked, coded and entered to Epi-data version 3.1 and exported to SPSS version 23 for analysis. The reliability of items used to measure male partner's involvement in MWH utilization, male partner's knowledge and attitude towards MWH were checked by Cronbach's alpha value. Binary logistic regression analysis was used to determine the association between explanatory variables and male partners' involvement in maternity waiting home utilization. Those candidate variables which were significant $(p<0.25)$ in the bi-variable analysis were entered to multivariable logistic regression analysis. Finally, adjusted odds ratio with $95 \%$ confidence intervals was used to identify independent predictors of male partners' involvement in maternity waiting home utilization.

\section{Ethical considerations}


Ethical clearance letter was obtained from Bahir Dar University College of Medicine and Health Sciences Institutional Review Board. Permission letter was obtained from North Achefer district administrative. Moreover, all the study participants were informed about the purpose and benefit of the study along with their right to refuse and verbal consent was obtained. The study participants were reassured for an attainment of confidentiality. We maintained anonymity and confidentiality of information throughout the study process.

\section{Results}

\section{Socio-demographic and economic characteristics of study participants}

Four hundred three male partners were involved in the study making a response rate of $91.2 \%$. Thirty seven percent males were between age groups of $40-49$. Majority, $96.8 \%$ of males were orthodox Christian followers. Ninety two percent were Amhara by ethnicity. Eighty one percent of males were farmers. About $49 \%$ of males were unable to read and write. Nearly, twenty two males were rich and $20.8 \%$ were poor (table 1).

\section{Obstetric histories of spouses of male partners}

With regards to obstetric history of spouses about $77.4 \%$ of their spouses gave birth before the current child. About $66.8 \%$ of their spouses had previous history of health facility delivery and $12.8 \% \mathrm{had}$ previous history of obstetric complications. The most common obstetric complications that occurred were hemorrhage (37.5\%) and prolonged labor (37.5\%). Eighty six percent of respondents' spouses stayed less than fifteen days at maternity waiting home for the current child. Eighty two percent of respondents' spouses had ANC follow up for the current child, of whom $73 \%$ of male partners accompanied their spouse during ANC follow up and $65.9 \%$ of male partners had received counseling during ANC about maternity waiting home (table 2).

\section{Male partners' gender thinking, knowledge and attitude towards $\mathrm{MWH}$}

Male partners were asked about gender thinking that likely influence their involvement to rest pregnant women in maternity waiting home: $17.1 \%$ think that childbirth is women affairs that do not need the participation of males, $16.1 \%$ think that child-birth is natural phenomenon that should not require males' much attention and $28.8 \%$ think that accompanying wife to maternity waiting home for delivery is women's responsibility. Forty-four percent of men make decision alone in any case that needs decision in the family. Almost all, $99 \%$ of men involved in the study had only one wife (table 3 ).

The Cronbach's alpha value of the knowledge questions was 0.755 . The Cronbach's alpha value of the attitude questions was 0.127 . As indicated in table $3,36.7 \%$ of respondents had positive attitude.

\section{Male partners' involvement on maternity waiting home}


The six items used to assess male partners' involvement in maternity waiting home utilization was evaluated by Cronbach's alpha value. The Cronbach's alpha was 0.727 . The mean and median of the items were 3.26 and 4 respectively.

Overall, $55.6 \%$ of male partners had good involvement on maternity waiting home utilization (figure 1). When we look at on specific male partners' involvement indicators, $56.3 \%$ of partners were decided to rest their spouse to $\mathrm{MWH}, 54.1 \%$ accompany their spouse while she went to $\mathrm{MWH}, 52.6 \%$ provide financial support while spouses went to/at maternity waiting home, $62.5 \%$ avail food while spouses were at MWH and $45.9 \%$ looked after the home and/or the remaining children while the spouses were at MWH (table 4).

\section{Factors influencing partner's involvement in maternity waiting home utilization}

In effort to identify predictor variables of male partners' involvement, we fitted multivariable logistic regression model. In the bi-variable logistic regression analysis, variables with p-value less than 0.25 were taken as candidate variables for multivariable logistic regression model. Thus, age, occupation, educational status, number of live children, wealth index, distance from maternity waiting home, duration of stay at maternity waiting home, knowledge about maternity waiting home, attitude towards maternity waiting home, decision making power of respondents, spousal ANC follow up, previous spousal health facility delivery, previous spousal obstetric complication, and receiving counseling about maternity waiting home during spousal ANC follow up were entered to multivariable model.

Based on findings from multivariable logistic regression analysis, a one year increase in male partners' age was associated to decrease in the likelihood of male partner involvement in maternity waiting home utilization by $12 \%(\mathrm{AOR}=0.88,95 \% \mathrm{Cl}=0.82-0.94)$. Knowledge of male partners related to maternity waiting home were positively associated with involvement in maternity waiting home utilization. A unit increase in the total score of knowledge was associated to an increase in the likelihood of involvement in maternity waiting home utilization by $4.75(\mathrm{AOR}=4.75,95 \% \mathrm{Cl}=2.65-8.49)$. Husbands who mostly made decisions in case that needs decision were 4 times more likely to be involved in MWHs compared to those decided equally after discussion ( $\mathrm{AOR}=4.00,95 \% \mathrm{Cl}=1.38-11.57$ ). Those male partners' who received counseling about maternity waiting home during spousal ANC follow up were 9 times more likely to be involved in maternity waiting home utilization compared to those who haven't received counseling (AOR=9.15, 95\% Cl = 3.34-25.03) (table 5).

\section{Discussion}

The study revealed that the proportion of male partners' involvements' in maternity waiting home utilization was $55.6 \%$ with $95 \% \mathrm{Cl}(50.71-60.45)$. Our study also identified that male partner's age, knowledge towards $\mathrm{MWH}$, decision making autonomy and receiving counseling were factors significantly influencing males' involvement in maternity waiting home utilization.

A 55\% proportion of male involvement in maternity waiting home utilization revealed by this study was low. It is assumed low because women's stay in MWH until the labour starts, which may take long time 
(few days to many weeks). Study done in Ethiopia reported that on average they stayed 14.8 days at the MWHs and about $40 \%$ of pregnant women stayed for two or more weeks [9]. If higher level of male partners' involvement is not achieved than the level we obtained now, likely compromises future use. The lack of men's support in their longer stay at MWH would become bad experience for women to have an intention to use or to recommend for others.

This study identified that being younger age is associated with increase male partner involvement in maternity waiting home utilization. This might be due to the changing caring attitude of younger men for their wife and would be born child, and reduced influence of patriarchal thinking among this age group compared to older men. This finding is consistent with study done in Lemo woreda of Ethiopia [16].

The current study found that male partner's knowledge was associated with an increase involvement in maternity waiting home utilization. Similarly, our study noted the positive association between receiving counseling about maternity waiting home during spousal ANC follow up and male involvement in maternity waiting home utilization. This might be due to the fact that having knowledge is prerequisite to practice. If men have awareness on the benefit package of maternity waiting home through different outlets including health worker counseling, they could be encouraged to involve in service uptake. This finding was consistent with other studies done on male involvement in delivery service and male involvement in birth preparedness and complication readiness in southern Ethiopia, Lemo distric of Ethiopia, Ambo town of Ethiopia, Mekelle town of Ethiopia, Enderta district of Ethiopia, Kenya, India and Mali $[13,17-24]$.

Men alone decision making in a family decision was positively associated with male involvement in MWHs use. This finding implies the presence of male dominance in the society. The finding is supported by qualitative study done in Zambia that even though the decision-making process regarding utilization of MWHs mainly involved the husband and wife sitting down to discuss, the final decision was made by the husband after taking into consideration of potential risks of labour complications[17]. This might be assumed that whenever male are the most decision makers in a family, they will have the power to allow/refuse their spouses to utilize maternal health services.

The study has limitations. Lack of standardized indicators/tools to measure male partner involvement in maternity waiting home utilization may be a limitation of the study.

\section{Conclusions}

Nearly, half of male partners showed poor involvement in maternity waiting home utilization. Men's knowledge towards $\mathrm{MWH}$, receiving counseling during spousal ANC visit, men alone decision making in family affairs, and being younger age were factors positively influenced male partners' involvement in maternity waiting home utilization. Interventions targeting to improve male involvement in maternity waiting home utilization shall focus on building men's knowledge about MWH and changing patriarchal thinking in the society. 


\section{Declarations}

\section{Ethics approval and consent to participate}

We obtained ethical approval letter from Institutional Review Board of Bahir Dar University College of Medicine and Health Sciences. Informed consent was also obtained from study participants.

\section{Consent for publication}

Not applicable

\section{Availability of data and material}

The datasets used and/or analyzed during the current study are available from the corresponding author on reasonable request.

\section{Competing interests}

The authors declare that they have no competing interests

\section{Funding}

There is no funding for this research

\section{Authors' contribution}

GA, conceived the research idea and developed the proposal, participated in data collection and analysis, and drafted the paper. DN, enriched the concept and proposal write up, participated in data analysis and drafting of the manuscript, and critically reviewed the manuscript. YD, enriched the concept and proposal write up, participated in data analysis, and critically reviewed the manuscript. All the authors read and approved the final manuscript.

\section{Acknowledgment}

We are very grateful to the Bahir Dar University for giving us the ethical clearance. We are also indebted to thank North Achefer district health office, kebeles administrations and study participants for their cooperation during data collection.

\section{References}

1. WHO: Making pregnancy safer : the critical role of the skilled attendant : a joint statement by WHO, ICM and FIGO. In: Making pregnancy safer. Geneva: World Health Organization, Department of Reproductive Health and Research; 2004.

2. Renfrew MJ, Homer C, Downe S, Mcfadden A, Muir NK, Prentice T, Hoope-Bender Pt: Midwifery: an executive summary for the Lancet's series. The Lancet 2014, 384:1-8. 
3. Central Statistical Agency (CSA) [Ethiopia] and ICF-International: Ethiopia Demographic and Health Survey 2016. In. Addis Ababa, Ethiopia and Rockville, Maryland, USA; 2016.

4. Figa'-Talamanca I: Maternal mortality and the problem of accessibility to obstetric care; the strategy of maternity waiting homes. Social Science \& Medicine 1996, 42(10):1381-1390.

5. Poovan P, Kifle F, Kwast BE: A maternity waiting home reduces obstetric catastrophes. World Health Forum 1990, 11:440-445.

6. World Health Organisation: Maternity Waiting Homes: A review of experiences. In. Geneva: WHO; 1996.

7. A G, L P, KW S: Maternity waiting homes in Ethiopia -three decades experience. Ethiop Med J 2012, 50(3):209-219.

8. Federal Ministry Health of Ethiopia: Guideline for maternity waiting home utilization. In.; 2017.

9. Tadele G, Wasie B: Maternity waiting homes in Rural Health Centers of Ethiop: The situation, women's experiences and challenges. Ethiopian Journal of Health Development 2016, 30(1):20-26.

10. Haile A, Enqueselassie F: Influence of Women's autonomy on couple's contraception use in Jimma town, Ethiopa, vol. 20; 2009.

11. World Health Organization (WHO): Programming for male involvement in reproductive health: Report of the meeting of WHO regional advisers in reproductive health WHO/PAHO, Washington, DC, USA, 57 September 2001. In. Geneva, Switzerland: WHO; 2002.

12. WHO: WHO recommendations on health promotion interventions for maternal and newborn health 2015. In. Geneva, Switzerland; 2015.

13. Mramba L, Nassir FA, Ondieki C, Kimanga D: Reasons for low utilization of a maternity waiting home in rural Kenya. International Journal of Gynecology \& Obstetrics 2010, 108(2):152-153.

14. Endalew GB, Gebretsadik LA, Gizaw AT: Intention to use Maternity Waiting Home among Pregnant Women in Jimma District, Southwest Ethiopia. Global Journal of Medical Research 2016, 16(6).

15. Noth-Achefer-Woreda-Health-Office: North Achefer woredas health office biannual report. In. Edited by health mac; 2018.

16. Nuradin A: assessment of male partners' involvement in promoting skilled delivery attendance of spouses and associated factors in Lemo woreda, Hadiya zone, southern nation nationality people region Ethiopia. In.: Addis Ababa University; 2014

17. Sialubanje C, Massar K, Kirch EM, Pijl MSGvd, Hamer DH, Ruiter RAC: Husbands囚 experiences and perceptions regarding the use of maternity waiting homes in rural Zambia. International Journal of Gynecology and Obstetrics 2015, 133(1):108-111.

18. Demissie DB, Bulto GA, Terfassa TG: Involvement of Male in Antenatal Care, Birth Preparedness and Complication Readinessand Associated Factors in Ambo Town, Ethiopia. Health, Medicine and Nursing 2016, 27.

19. Weldearegay HG: Determinant Factors of Male Involvement in Birth Preparedness and Complication Readiness at Mekelle Town; a community Based Study. Science Journal of Public Health 2015, 
3(2):175-180.

20. Nanjala M, Wamalwa D: Determinants of Male Partner Involvement in Promoting Deliveries by Skilled Attendants in Busia, Kenya. Global Journal of Health Science 2012, 4(2):60-67.

21. Smith K, Dmytraczenko T, Mensah B, Sidibe O: Knowledge attitudes and practices related to maternal health in Bla Mali: results of a baseline survey. In: . Bethesda, MD: The Partners for Health Reformplus Project, Abt Associates Inc.; 2004.

22. Chattopadhyay A: Men in maternal care: evidence from India. Journal of biosocial science 2012, 44(2):129-153.

23. Vermeiden T, Braat F, Medhin G, Gaym A, Akker Tvd, Stekelenburg J: Factors associated with intended use of maternity waiting home in Southern Ethiopia. BMC Pregnancy and Childbirth 2018, 18(38).

24. Gebrehiwot H, Gebregziabher W, Gidey G: Assessment of Husbands' Participation on Birth Preparedness and Complication Readiness in Enderta Woreda, Tigray Region, Ethiopia, 2012. Journal of Women's Health Care 2013, 3(140).

\section{Tables}

Table 1. Socio-demographic characteristics of study participants in North Achefer district, Northwest Ethiopia, 2018 


\begin{tabular}{ccc}
\hline Variables & Frequency & Percentage \\
\hline $\begin{array}{c}\text { Age category } \\
18-29\end{array}$ & 77 & 19.1 \\
$30-39$ & 91 & 22.6 \\
$40-49$ & 149 & 37.0 \\
$>=50$ & 86 & 21.3
\end{tabular}

\section{Educational status}

Unable to read and write $196 \quad 48.6$

$\begin{array}{lll}\text { Read and write only } & 82 & 20.3\end{array}$

$\begin{array}{lll}\text { Primary education } & 65 & 16.1\end{array}$

$\begin{array}{lll}\text { Secondary education } & 12 & 3.1\end{array}$

$\begin{array}{lll}\text { Higher education } & 48 & 11.9\end{array}$

\section{Occupation}

$\begin{array}{lll}\text { Farmer } & 326 & 80.9 \\ \text { Merchant } & 27 & 6.7 \\ \text { Government employee } & 50 & 12.4\end{array}$

Number of living children

\begin{tabular}{ccc}
\hline 1 & 94 & 23.3 \\
\hline $2-4$ & 138 & 34.3 \\
$>=5$ & 171 & 42.4 \\
\hline Wealth index quintile & & \\
\hline Very rich & 80 & 19.9 \\
\hline Rich & 88 & 21.8 \\
\hline Middle & 74 & 18.4 \\
\hline Poor & 84 & 20.8 \\
\hline Very poor & 77 & 19.1 \\
\hline
\end{tabular}


Table 2. Study participant's spousal obstetric history in North Achefer district, 2018 
Previous delivery history

Yes

No

Previous health facility delivery

Yes

No

Previous history of obstetric complication

Yes

No

Types of obstetric complications

Preterm labour

Premature rapture of membrane

Hemorrhage

Prolonged labor

Previous still-birth history

Yes

No

Duration of stay at MWHs

$<15$ days

15-30 days

Spousal ANC visit

Yes

331

72

347

56

86.1

No

Male partner accompaniment during ANC visit

Yes

No

Male partners got counseling about MWH during $4^{\text {th }}$ visit

Yes
312

77.4

22.6
66.8

33.2
87.2

2

5.0

8

20.0

15

37.5

15

37.5

11

3.5

302

96.5
13.9 
Table 3. Male partners' gender thinking and attitude towards maternity waiting home in North Achefer district, 2018 
Child-birth is a woman's affairs that does not require men participation

Yes

No

Child-birth is natural phenomenon that should not be given much attention by males

Yes

65

16.1

No

Accompanying wife to maternity waiting home for delivery is women's responsibility

Yes

No

Who is the most decision maker in your family in any case that needs decision?

Male alone

Wife alone

Spouses jointly
179

50

174
44.4

12.4

43.2

Male partners having more than one wife other than the current wife living together

Yes

No

Attitude

Positive attitude

Negative attitude
148

36.7

255
1.0

99.0

Table 4. Distribution of male partners' involvement on maternity waiting home utilization in North Achefer district, 2018 
Decided their spouse to rest in MWH for current Child

Yes

No
227

176

218

185
56.3

43.7

Accompany their spouses for resting in $\mathrm{MWH}$ for current child

Yes

No

Provided financial support for their spouse while they went

to/were at MWH for the current child

Yes

212

52.6

No

191

47.4

Availed food when their spouse and relatives were at MWHs

Yes

252

62.5

No

151

37.5

Looked after the home and or children while their spouses were at

MWHs for the current child

Yes

No

Arranged transport when their spouse went to MWHs
218

185
45.9

54.1
Yes

No
185

218
54.1

45.9

Table 5. Factors affecting male partners' involvement in maternity waiting home utilization in North Achefer district, 2018 


\begin{tabular}{|c|c|c|c|c|}
\hline \multirow[t]{2}{*}{ Variables } & \multicolumn{2}{|c|}{$\begin{array}{l}\text { Male } \\
\text { involvement }\end{array}$} & \multirow[t]{2}{*}{ COR(95\% CI) } & \multirow[t]{2}{*}{ AOR(95\% CI) } \\
\hline & Good & Poor & & \\
\hline Age in year & & & $0.86(0.84,0.89)$ & $0.86(0.82,0.94)^{* *}$ \\
\hline Knowledge score & & & $8.57(5.29,13.87)$ & $4.74(2.65,8.49)^{* *}$ \\
\hline \multicolumn{5}{|c|}{ Most decision maker in family } \\
\hline \multicolumn{5}{|l|}{ decision } \\
\hline Male alone & $31.8 \%$ & $12.7 \%$ & $2.18(1.41,3.40)$ & $4.00(1.38,11.57) *$ \\
\hline Wife alone & $0.7 \%$ & $11.7 \%$ & $0.06(0.02,0.19)$ & $0.29(0.05,1.75)$ \\
\hline Partners jointly & $23.1 \%$ & $20 \%$ & 1 & 1 \\
\hline \multirow{2}{*}{\multicolumn{5}{|c|}{$\begin{array}{l}\text { Male partners got counseling } \\
\text { about maternity waiting home }\end{array}$}} \\
\hline & & & & \\
\hline Yes & $55 \%$ & $10.9 \%$ & $19.78(11.07,35.36)$ & $9.15(3.34,25.03)^{* *}$ \\
\hline No & $6.9 \%$ & $27.2 \%$ & 1 & 1 \\
\hline
\end{tabular}

COR crude odds ratio, AOR adjusted odds ratio, * indicate variables which are significant at $p<0.05, * *$ indicate variables which are significant at $p<0.001$

Figures 
60

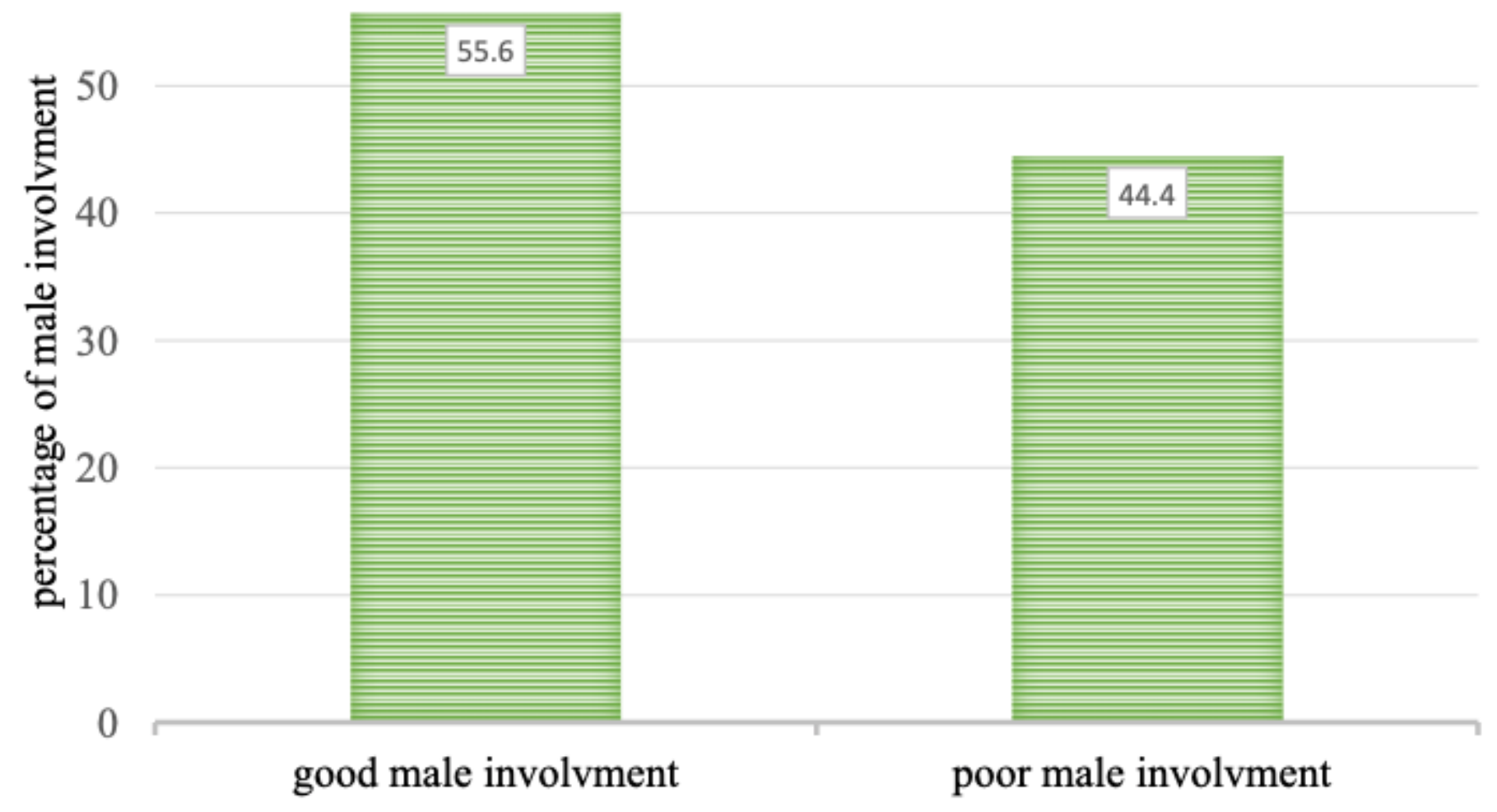

Figure 1

Percentage distribution of overall male partners' involvement in MWH, North Achefer district, 2018 